\title{
Synthesis and spectral properties of fluorescent dyes based on 4-styryl-1,8-naphthalimide
}

\author{
P. A. Panchenko, ${ }^{\star \star}$ A. N. Arkhipova, ${ }^{a}$ M. A. Zakharko, ${ }^{a}$ G. Jonusauskas, ${ }^{b}$ Yu. V. Fedorov, ${ }^{a}$ and O. A. Fedorova ${ }^{a}$ \\ ${ }^{a}$ A. N. Nesmeyanov Institute of Organoelement Compounds, Russian Academy of Sciences, \\ 28 ul. Vavilova, 119991 Moscow, Russian Federation. \\ Fax: +7(495) 135 5085. E-mail: pavel@ineos.ac.ru \\ ${ }^{b}$ Centre de Physique Moléculaire Optique et Hertzienne (CPMOH), \\ Université Bordeaux 1, UMR CNRS 5798, \\ 351 Cours de la Libération, 33405 Talence, France
}

\begin{abstract}
The paper reports on synthesis and spectroscopic study of novel $N$-butyl-4-styryl-1,8-naphthalimide dyes bearing methoxy (1), dimethoxy (2), and dimethylamino (3) groups in the styryl fragment. It is shown that all synthesized compounds demonstrate positive solvatochromism, high values of Stokes shift in polar solvents, and fluorescence in the long wavelength part of visible range. These facts indicate a potential application of these compounds as fluorescent dyes in the biochemistry. The changes in the dipole moments of the molecules caused by excitation were estimated using Lippert-Mataga equation. The obtained results could be assigned to the formation of the excited states with intramolecular charge transfer. The formation of the twisted states with charge transfer was suggested in the case of compound $\mathbf{3}$, while the fluorescence quantum yield was significantly reduced in polar protic solvents.
\end{abstract}

Key words: naphthalimide, styryl dyes, intramolecular charge transfer, twisted intramolecular charge transfer, solvatochromism, fluorescence, Lippert-Mataga equation.

Nowadays, the methods of fluorescence spectroscopy are of great importance for the application in biological and biomedical research. ${ }^{1}$ With the appearance of confocal fluorescence microscopy ${ }^{2}$ the organic fluorophores have been used as molecular probes, imaging reagents, and sensors, allowing one to study the structure, dynamics, and function of biological macromolecules. ${ }^{3-6}$ It is known that the emission peaks of the most intensively luminescent organic materials are located in a range of $400-600 \mathrm{~nm}$. This spectral range is characterized by significant absorption of the excitation light by the biological sample. In addition, there is relatively strong fluorescent background in this spectral range, which greatly limits the choice of useful photoactive compounds.

Cyanine dyes ${ }^{7-9}$ are used in many cases for in vivo optical studies, because at relatively small length of conjugated chain (about seven methine groups) their fluorescence maxima may be located near the border of the visible and near infrared (NIR) spectral regions, or even be in the NIR range. The disadvantages of the cyanine dyes include the complexity of their synthesis, relatively low photochemical stability, and low values of the Stokes shift, which usually do not exceed $25 \mathrm{~nm}$. The latter feature of the spectral properties is not desirable when using the confocal fluorescence microscopy, since it leads to a significant reduction in the contrast of the images due to reflection/scattering of the excitation light by the test sample.

The derivatives of imide of naphthalic acid (1,8-naphthalimide) are practically important class of organic fluorophores, which are used in many areas of science and technology, such as optical brightening, ${ }^{\mathbf{1 0}}$ fluorescent crack detection, ${ }^{\mathbf{1 1}}$ solar energy conversion, ${ }^{\mathbf{1 2}}$ fabrication of the optical memory elements, ${ }^{\mathbf{1 3}}$ and electroluminescent devices. ${ }^{14}$ Intensive fluorescence in the visible spectrum, high photostability, and high values of Stokes shift of 1,8-naphthalimides along with the simplicity of synthetic modifications aimed to molecular structure of this type make these compound attractive for the application as a photoactive component of ratiometric chemosensors suitable for the analysis of ions in living cells ${ }^{\mathbf{1 5}, 16}$ as well as fluorescent dyes for applications in biology and medicine. ${ }^{17,18}$

It has been shown in earlier works devoted to the spectroscopic study of 1,8-naphthalimide derivatives that the introduction of polarizing substituents having strong electron donating properties in positions 4 and 5 of the naphthalene nucleus leads to a bathofluoric shift of the emission band. ${ }^{19,20}$ In most cases, the 4-substituted derivatives formed at this exhibit blue or yellow-green emission $\left(\lambda_{\max }=450-550 \mathrm{~nm}\right)$. Much rarely the compounds are found, in which naphthalimide chromophore 
emits at longer wavelength region of the spectrum $\left(\lambda_{\max }>\right.$ $>600 \mathrm{~nm}) .{ }^{21-23}$ Exactly such derivatives are of the greatest practical interest for the study of biological samples with fluorescent methods.

In this paper, the synthesis and detailed study of spectral-luminescent properties of 1,8-naphthalimides 1-3 (Scheme 1), containing styryl fragment at atom C(4) and differing in the number and nature of the electron donating substituent in the phenyl ring, are considered. Such compounds are able to enter cells. They have potential use as in vivo fluorescent imaging reagents. ${ }^{23}$ However, their optical properties were investigated in a lesser extent than the properties of 4-amino, 4- (acyl)amino, and 4-alkoxy1,8-naphthalimides.

\section{Scheme 1}
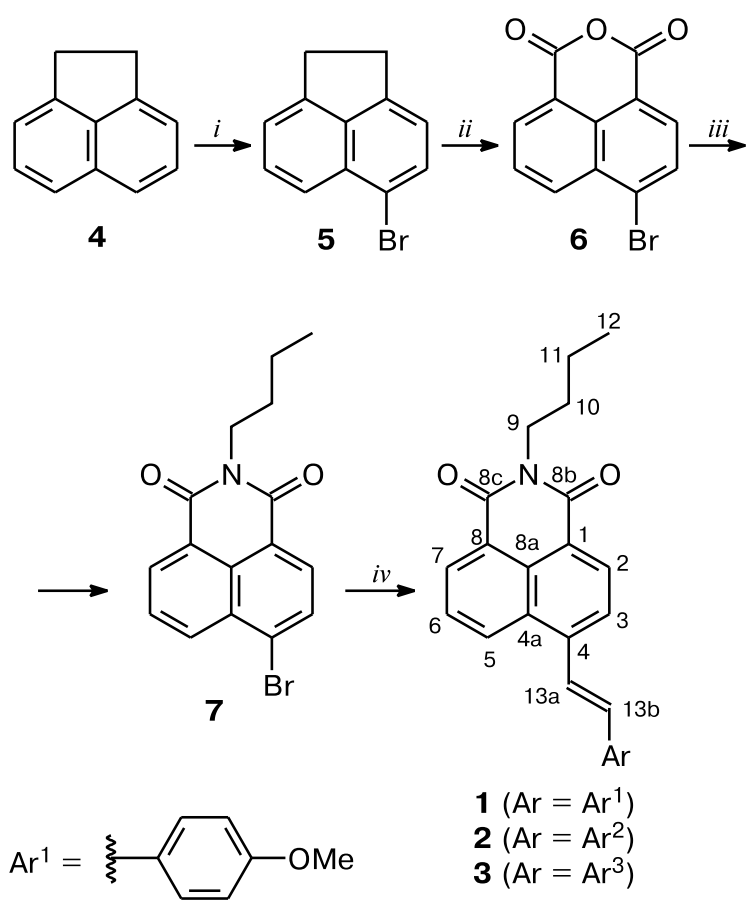

$1\left(\mathrm{Ar}=A r^{1}\right)$

$2\left(\mathrm{Ar}=A r^{2}\right)$

$3\left(\mathrm{Ar}=A r^{3}\right)$

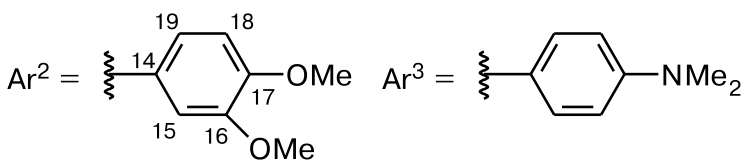

i. NBS, DMF, 82\%; ii. $\mathrm{Na}_{2} \mathrm{Cr}_{2} \mathrm{O}_{7}, \mathrm{AcOH}, \Delta, 44 \%$; iii. $\mathrm{Bu}^{\mathrm{n}} \mathrm{NH}_{2}$, EtOH, $\Delta, 89 \% ; i v$. $\mathrm{Ar}-\mathrm{CH}=\mathrm{CH}_{2},(o-\mathrm{Tol})_{3} \mathrm{P}, \mathrm{Pd}(\mathrm{OAc})_{2}$, DMF, $\Delta, 18-38 \%$.

\section{Results and Discussion}

Target 4-styryl substituted derivatives of 1,8-naphthalimide $\mathbf{1}-\mathbf{3}$ were prepared starting from acenaphthene
(4) according to Scheme 1. The bromination of 4 to 4-bromo acenaphthene (5) followed by the oxidation led to 4-bromonaphthalic anhydride (6), which further was converted to naphthalimide 7 using $n$-butylamine in ethanol. The introduction of styryl fragment into position 4 of the naphthalimide nucleus at the final step was carried out by the Heck reaction using commercially available styrene derivatives. ${ }^{24}$ The structures and compositions of prepared compounds $\mathbf{1} \mathbf{- 3}$ were proved by a combination of physico-chemical analytic techniques (see Experimental).

The absorption and fluorescence emission spectra of naphthalimides 1-3 were registered in fifteen different solvents, among them were five protic and ten aprotic solvents. Stokes shifts $(\Delta \widetilde{v})$, fluorescence quantum yields $\left(\varphi^{\mathrm{fl}}\right)$, and excited state lifetimes $(\tau)$ were also determined. The data are presented in the Table 1.

The long wavelength band in the absorption spectra of investigated compounds is connected to intramolecular charge transfer (ICT) from electron donating styryl fragment to carbonyl groups of dicarbonylimide moiety as evidenced by the distribution of electron density in the frontier molecular orbitals (HOMO and LUMO) of 1-3 (Fig. 1). As examples the absorption and fluorescence spectra of $\mathbf{1 - 3}$ in ethyl acetate are presented in the Fig. 2. It is clear from Fig. 2 that an increase of electron donating properties of the substitutent in the position 4 of the naphthalene ring from monomethoxy derivative $\mathbf{1}$ to dimethoxystyrylnaphthalimide $\mathbf{2}$ and further to $\mathbf{3}$ leads to the bathochromic shift, which corresponds to convergence of energy levels $S_{0}$ and $S_{1}$ and an increase of the efficiency of the formation of the ICT-state.

An increase in the solvent polarity and its ability to form hydrogen bonds also causes displacement of the maxima of absorption bands ( $\lambda_{\text {max }}^{\text {abs }}$ ) and fluorescence $\left(\lambda^{\mathrm{fl}}{ }_{\text {max }}\right)$ to longer wavelength with simultaneous growth of $\Delta \widetilde{v}$ value (see Table 1). Significant solvatochromism and solvatofluorochromism of 4-styrylnaphthalimide derivatives allowed estimation of the change of dipole moment of these molecules upon the transition into excited state. The Lippert-Mataga equation ${ }^{\mathbf{2 5 , 2 6}}$ was used for the analysis of influence of solvent on the emission spectra of the compounds under investigation:

$$
\begin{aligned}
& \Delta \widetilde{v}=\widetilde{v}_{\mathrm{abs}}-\widetilde{v}_{\mathrm{fl}}=\frac{2\left(\mu_{\mathrm{e}}-\mu_{\mathrm{g}}\right)^{2}}{h c a^{3}}\left[\frac{\varepsilon-1}{2 \varepsilon+1}-\frac{n^{2}-1}{2 n^{2}+1}\right]+\text { const } \\
& \Delta f=\frac{\varepsilon-1}{2 \varepsilon+1}-\frac{n^{2}-1}{2 n^{2}+1}
\end{aligned}
$$

where $\Delta \widetilde{v}$ is the Stokes shift, $\mathrm{cm}^{-1} ; \Delta \widetilde{v}_{\mathrm{abs}}, \Delta \widetilde{v}_{\mathrm{fl}}$ are the wave numbers corresponding to spectral maxima in absorption and fluorescence spectra, respectively, $\mathrm{cm}^{-1}$; 
Table 1. Absorption spectra data and fluorescent characteristics of compounds $\mathbf{1}-\mathbf{3}$ in different solvents at $20^{\circ} \mathrm{C}$

\begin{tabular}{|c|c|c|c|c|c|c|c|c|}
\hline $\begin{array}{l}\text { Com- } \\
\text { pound }\end{array}$ & Solvent & $\varepsilon$ & $\lambda^{\mathrm{abs}} \max / \mathrm{nm}$ & $\begin{array}{c}\varepsilon_{\lambda} \cdot 10^{-3} \\
/ \mathrm{L} \mathrm{mol}^{-1} \mathrm{~cm}^{-1}\end{array}$ & $\lambda_{\text {max }}^{\mathrm{fl}}\left(\lambda_{\mathrm{ex}}\right) / \mathrm{nm}$ & $\Delta \tilde{\mathrm{v}} / \mathrm{sm}^{-1}$ & $\varphi^{\mathrm{fl}}$ & $\tau / \mathrm{ns}$ \\
\hline \multirow[t]{15}{*}{1} & Propylene carbonate & 65.0 & 411 & 22.1 & $579(370)$ & 7060 & 0.33 & 2.51 \\
\hline & Dimethylsulfoxide & 46.7 & 421 & 23.1 & $589(420)$ & 6775 & 0.41 & 3.05 \\
\hline & Acetonitrile & 37.5 & 406 & 22.8 & $570(365)$ & 7087 & 0.33 & 2.35 \\
\hline & Acetone & 20.7 & 408 & 23.9 & $557(400)$ & 6556 & 0.28 & 2.10 \\
\hline & 3-Methylbutane-2-one & 16.1 & 409 & 22.9 & $549(400)$ & 6235 & 0.25 & 1.95 \\
\hline & 4-Methylpentane-2-one & 13.1 & 410 & 21.9 & $544(435)$ & 6008 & 0.24 & 1.80 \\
\hline & 1,2-Dimethoxyethane & 7.2 & 408 & 22.7 & $544(350)$ & 6127 & 0.26 & 1.85 \\
\hline & Ethyl acetate & 6.0 & 405 & 23.2 & $527(365)$ & 5716 & 0.25 & 1.45 \\
\hline & Diethyl ether & 4.3 & 402 & 23.5 & $504(365)$ & 5034 & 0.21 & 1.08 \\
\hline & Cyclohexane & 1.9 & 398 & 21.8 & $450(365)$ & 2903 & 0.33 & 1.02 \\
\hline & Methanol & 32.7 & 413 & 23.2 & $603(350)$ & 7629 & 0.79 & 2.67 \\
\hline & Ethanol & 24.6 & 413 & 23.7 & $588(350)$ & 7206 & 0.57 & 2.87 \\
\hline & $n$-Butanol & 17.5 & 415 & 22.2 & $577(350)$ & 6765 & 0.44 & 2.62 \\
\hline & $n$-Hexanol & 13.3 & 415 & 22.7 & $585(350)$ & 7002 & 0.44 & 2.53 \\
\hline & $n$-Decanol & 8.1 & 415 & 21.8 & $568(350)$ & 6491 & 0.41 & 2.48 \\
\hline \multirow[t]{15}{*}{2} & Propylene carbonate & 65.0 & 418 & 30.2 & $610(400)$ & 7530 & 0.51 & 3.06 \\
\hline & Dimethylsulfoxide & 46.7 & 429 & 28.0 & $620(400)$ & 7181 & 0.40 & 3.15 \\
\hline & Acetonitrile & 37.5 & 412 & 28.3 & $606(380)$ & 7770 & 0.43 & 3.80 \\
\hline & Acetone & 20.7 & 415 & 28.5 & $592(350)$ & 7204 & 0.50 & 4.02 \\
\hline & 3-Methylbutane-2-one & 16.1 & 416 & 28.2 & $579(370)$ & 6767 & 0.51 & 3.83 \\
\hline & 4-Methylpentane-2-one & 13.1 & 417 & 27.4 & $574(370)$ & 6559 & 0.54 & 3.70 \\
\hline & 1,2-Dimethoxyethane & 7.2 & 416 & 28.1 & $574(360)$ & 6617 & 0.50 & 3.43 \\
\hline & Ethyl acetate & 6.0 & 413 & 28.6 & $551(400)$ & 6064 & 0.41 & 3.13 \\
\hline & Diethyl ether & 4.3 & 408 & 30.1 & $523(360)$ & 5389 & 0.42 & 2.08 \\
\hline & Cyclohexane & 1.9 & 405 & 24.9 & $461(400)$ & 2999 & 0.27 & 1.29 \\
\hline & Methanol & 32.7 & 417 & 29.2 & $638(390)$ & 8307 & 0.040 & 0.33 \\
\hline & Ethanol & 24.6 & 419 & 28.1 & $621(400)$ & 7763 & 0.16 & 1.22 \\
\hline & $n$-Butanol & 17.5 & 421 & 27.8 & $619(400)$ & 7598 & 0.30 & 2.04 \\
\hline & $n$-Hexanol & 13.3 & 420 & 27.0 & $605(390)$ & 7281 & 0.47 & 2.81 \\
\hline & $n$-Decanol & 8.1 & 421 & 26.7 & $578(400)$ & 6452 & 0.57 & 3.20 \\
\hline \multirow[t]{15}{*}{3} & Propylene carbonate & 65.0 & 469 & 30.7 & $755(469)$ & 8077 & 0.021 & 0.27 \\
\hline & Dimethylsulfoxide & 46.7 & 485 & 32.1 & $776(480)$ & 7732 & 0.019 & 0.29 \\
\hline & Acetonitrile & 37.5 & 462 & 31.7 & $743(400)$ & 8186 & 0.032 & 0.38 \\
\hline & Acetone & 20.7 & 465 & 31.3 & $721(400)$ & 7639 & 0.092 & 1.05 \\
\hline & 3-Methylbutane-2-one & 16.1 & 468 & 31.0 & $705(400)$ & 7183 & 0.18 & 1.90 \\
\hline & 4-Methylpentane-2-one & 13.1 & 468 & 29.8 & $695(400)$ & 6979 & 0.25 & 2.56 \\
\hline & 1,2-Dimethoxyethane & 7.2 & 465 & 30.0 & $689(400)$ & 6992 & 0.19 & 1.68 \\
\hline & Ethyl acetate & 6.0 & 460 & 31.4 & $660(425)$ & 6588 & 0.38 & 3.65 \\
\hline & Diethyl ether & 4.3 & 453 & 32.4 & $608(510)$ & 5628 & 0.36 & 3.03 \\
\hline & Cyclohexane & 1.9 & 446 & 27.9 & $511(450)$ & 2852 & 0.21 & 0.88 \\
\hline & Methanol & 32.7 & 470 & 27.9 & $746(430)$ & 7872 & 0.0063 & 0.025 \\
\hline & Ethanol & 24.6 & 473 & 29.3 & $736(470)$ & 7555 & 0.019 & 0.082 \\
\hline & $n$-Butanol & 17.5 & 476 & 26.6 & $750(470)$ & 7675 & 0.037 & 0.20 \\
\hline & $n$-Hexanol & 13.3 & 476 & 27.8 & $702(470)$ & 6632 & 0.13 & 0.44 \\
\hline & $n$-Decanol & 8.1 & 475 & 28.5 & $668(470)$ & 6083 & 0.15 & 1.05 \\
\hline
\end{tabular}

Notes: $\varepsilon$ is the solvent dielectric constant; $\lambda_{\text {max }}^{\text {abs }}$ and $\lambda_{\text {max }}^{\mathrm{fl}}$ are the maxima in absorption and fluorescence spectra, respectively; $\varepsilon_{\lambda}$ is the extinction coefficient in the point corresponding to $\lambda_{\text {max }}^{\text {abs }} \lambda_{\text {ex }}$ is the excitation wavelength; $\Delta \widetilde{v}$ is the Stokes shift; $\varphi^{\mathrm{fl}}$ is the fluorescence quantum yield; $\tau$ is the excited state lifetime.

$\mu_{\mathrm{e}}$ and $\mu_{\mathrm{g}}$ are the dipole moments of compound in solution in excited and ground states, respectively, $\mathrm{D}(1 \mathrm{D}=$ $\left.=1 \cdot 10^{-18} \mathrm{~cm}^{5 / 2} \mathrm{~g}^{1 / 2} \mathrm{~s}^{-1}\right) ; h$ is the Planck constant ( $\left.h=6.626 \cdot 10^{-27} \mathrm{erg} \mathrm{s}\right) ; c$ is the speed of light in vacuum $\left(c=2.998 \cdot 10^{10} \mathrm{~cm} \mathrm{~s}^{-1}\right) ; a$ is the effective radius of
Onsager cavity (radius of cavity, where fluorophore is placed), $\mathrm{cm} ; \varepsilon$ and $n$ are the dielectric permittivity and refractive index of solvent, respectively; $\Delta f$ is the orientation polarizability of solvent. Equation (2) is given in CGS system. 

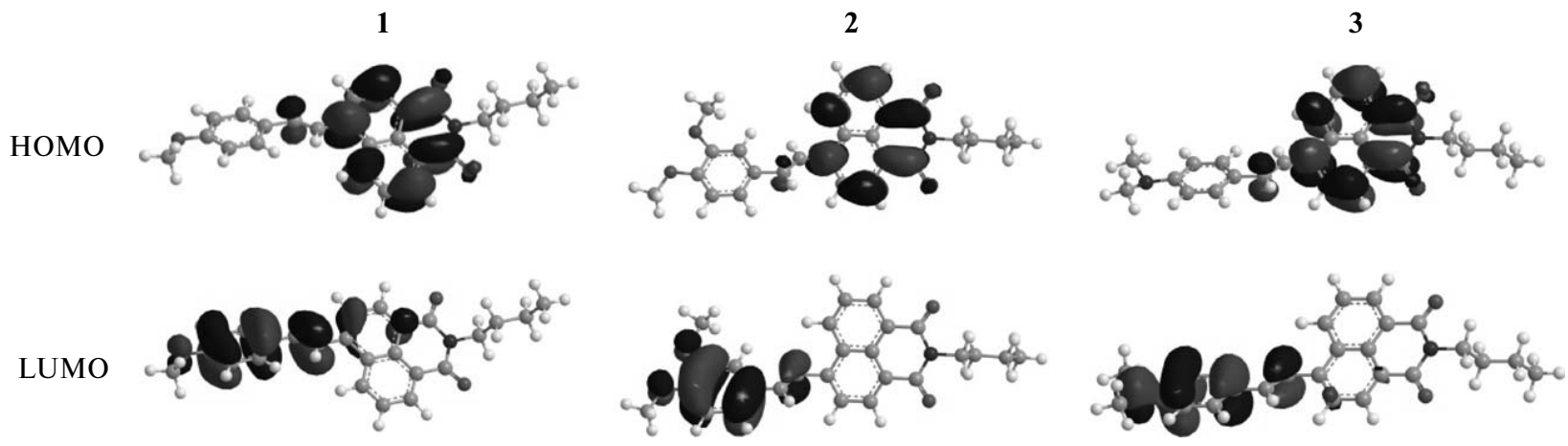

Fig. 1. Distribution of electron density of the frontier orbitals HOMO and LUMO of compounds 1-3. Data obtained by calculation with PM6 method.

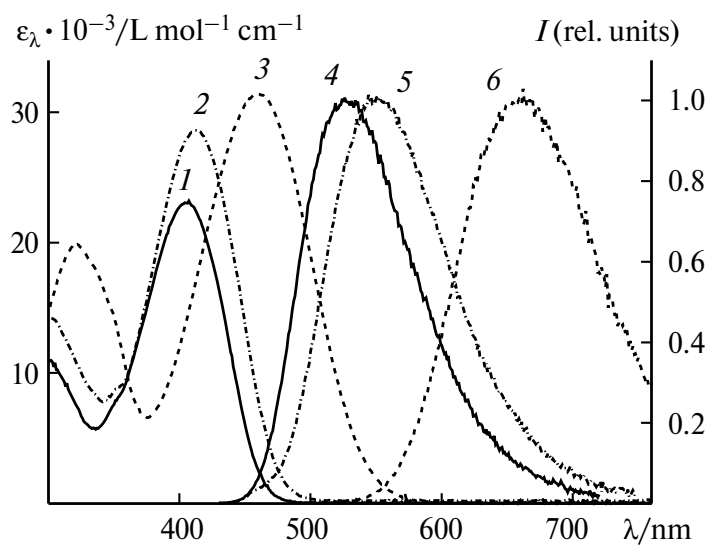

Fig. 2. Absorption spectra (1-3) and normalized fluorescence emission spectra (4-6) of compounds $\mathbf{1}(1,4), \mathbf{2}(2,5)$, and $\mathbf{3}(3,6)$ in ethyl acetate.

The values of parameter $\Delta f$ for used here protic and aprotic solvents and corresponding values of Stokes shifts for compounds $\mathbf{1 - 3}$ are represented in the Fig. 3. In considered cases both protic and aprotic solvents demonstrate good linear correlation. The changes of dipole moments upon the transition into excited state were determined using the slope of the lines in the Fig. 3. Calculated values $\left(\mu_{\mathrm{e}}-\mu_{\mathrm{g}}\right)$ consisted of 20.78, 21.96, and 22.95 D for 1, 2, and 3, respectively. Half of the distance between $\mathrm{N}$ atom or $\mathrm{O}$ atom in para-position to double bond in styryl fragment and $\mathrm{O}$ atom farthest from $\mathrm{C}(4)$ substitutent of carbonyl group was taken as the radius of the Onsager cavity. This is similar to approach taken for 4-substituted naphthalimide derivative earlier. ${ }^{27,28}$ The data of quantum chemical calculations for the compounds $\mathbf{1 - 3}$ by PM6 method (MOPAC-2012) were used to determine this distance. The values of $a$ for investigated fluorophores consisted of 6.85 (1), 6.80 (2), and $6.89 \AA$ (3).

It is known that a value of $4.8 \mathrm{D}$ corresponds to the dipole moment arising in the separation of unit charges at a distance of $1 \AA$. Consequently, the change of dipole moment of molecules $\mathbf{1}, \mathbf{2}$, and $\mathbf{3}$ at the excitation by values of $20.78,21.96$, and $22.95 \mathrm{D}$ corresponds to the separation of unit charges by a distance of $4.33,4.58$, and 4.78 A. Such character of the electronic density distribution upon absorption of light signifies the formation of excited states with charge transfer and corresponds to the values of $\left(\mu_{\mathrm{e}}-\mu_{\mathrm{g}}\right)$, obtained ${ }^{27-31}$ for naphthalimides derivative, containing different electron donating groups in the position 4 of naphthalimide nucleus.

The fluorescence quantum yield of compounds $\mathbf{1}-\mathbf{3}$ is changed differently by varying the nature of the solvent. In the case of compounds $\mathbf{1}$ and $\mathbf{2}$ the efficiency of radiative deactivation is approximately the same in both polar and non-polar solvents, while for compound $\mathbf{3}$ the growth of solvent polarity and its proton donating properties causes the fluorescence quenching (see Table 1). A similar dependence can be traced also for the excited states lifetime values. These observations point to the persistence of radiative rate constant of studied compounds in solvents of different nature, as well as to suggestion for compound $\mathbf{3}$ on the existence of relaxation channel, constituting a significant competition to the fluorescence in a polar environment.

According to current concepts, to explain the low $\varphi^{\text {fl }}$ values for fluorophores of ICT-type in polar protic solvents the model that postulates the formation of a twisted state of the charge-transfer (twisted intramolecular charge transfer - TICT) ${ }^{32}$ can be involved. This model assumes the existence of two energy minima on the potential energy surface of the excited state: the first one corresponds to locally excited state with quasi-planar arrangement of $\pi$-system and the donor group $\left(\mathrm{Me}_{2} \mathrm{NC}_{6} \mathrm{H}_{4}\right.$ in the case of naphthalimide 3); the second one corresponds to a state with a charge transfer from a donor to an acceptor group with quasi-perpendicular location of $\pi$-system and the donor group. In the frameworks of TICT model the formation of twisted state with charge transfer includes two steps: the charge transfer and following rotation of donor in respect to the rest of the molecule. TICT model has been suggested for the description of two band fluorescence of 4- $N, N$-dimethylaminobenzonitrile. ${ }^{33,34}$ How- 

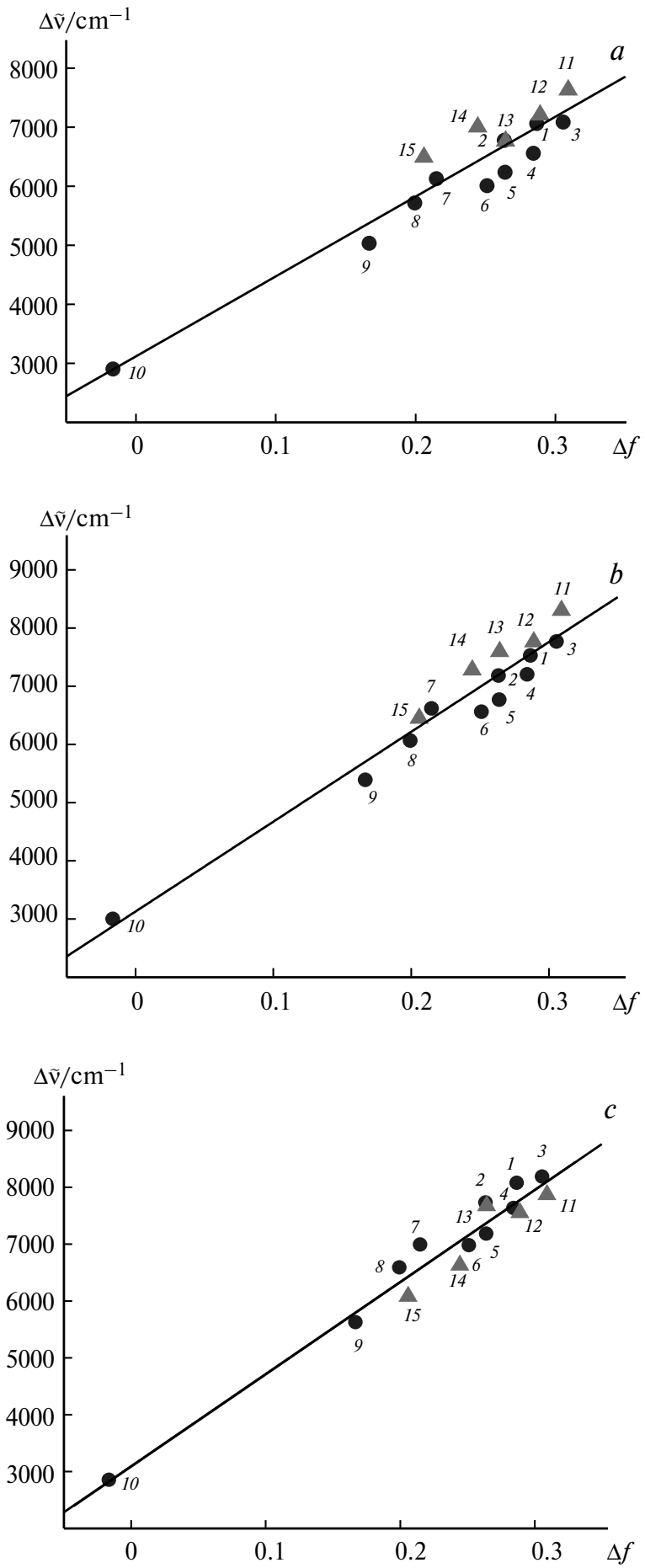

Fig. 3. Dependence of Stokes shift on polarity function of solvent for compounds $\mathbf{1}(a), \mathbf{2}(b)$, and $\mathbf{3}(c)$. Strait lines correspond to linear correlation between these parameters. The approximation of the data was obtained by least square method, correlation coefficients consist of $0.955,0.974$, and 0.978 for $\mathbf{1}, \mathbf{2}$, and $\mathbf{3}$, respectively. Solvents: 1 , propylene carbonate; 2 , dimethylsulfoxide; 3 , acetonitrile; 4, acetone; 5, 3-methylbutane-2-one; 6, 4-methylpentane2-one; 7, 1,2- dimethoxyethane; 8 , ethyl acetate; 9 , diethyl ether; 10, cyclohexane; 11, methanol; 12, ethanol; 13, n-butanol; 14, $n$-hexanol; 15, $n$-decanol. ever, in most cases the TICT states relax nonradiative and their formation decreases the quantum yield and fluorescence decay time. ${ }^{32}$ Apparently, the transition to TICT state is more probable for compound $\mathbf{3}$ than for compounds 1 and 2 because 4-(dimethylamino)styryl group, having the highest electron donating effect, contributes significantly to the charge separation during photoexcitation. It should be stressed out again that another factor (in addition to the electronic effects of substituents in the chromophore), which promote the formation of the twisted state is the solvation. In a strongly polar solvent the formation of non-fluorescent TICT form may be the dominant process. In particular, this results in a significant decrease in fluorescence quantum yield and lifetime of the excited state for compound $\mathbf{2}$ in methanol (see Table 1).

Thus, in the course of this work the naphthalimides 1-3, differing in the structure of the styryl moiety, were synthesized. The analysis of spectral-luminescent properties showed that all three compounds are ICT-fluorophores and exhibit significant solvatochromism. The absorption maxima $(400-420 \mathrm{~nm})$ and the fluorescence maxima $(500-570 \mathrm{~nm})$ of monometoxy derivative 1 are located at approximately the same wavelengths as in the case of 4-aminonaphthalimide. ${ }^{19}$ As it is noted above, 4-aminonaphthalimide has substantial limitations for using as a fluorescent component of molecular devices in biochemical research. 4-( $N, N$-Dimethylamino) styryl substituted compound $\mathbf{3}$ is the most long-wavelength fluorophore. However, the fluorescence quantum yield of this compound is low in proton polar environment due to the high probability of formation of twisted state with charge transfer. At the same time, it was shown that the presence of two electron donating methoxy groups in the phenyl nucleus in compound $\mathbf{2}$ leads to bathofluoric shift of the maximum to a value of 550-630 nm while maintaining high fluorescent signal intensity in polar solvents.

\section{Experimental}

${ }^{1} \mathrm{H}$ NMR spectra were registered using Avance-400 and Avance600 spectrometers (Bruker). The solutions were prepared in deuterated benzene, dimethylsulfoxide, and chloroform. The chemical shift of nuclei ${ }^{1} \mathrm{H}$ and ${ }^{13} \mathrm{C}$ were determined with deviation of $0.01 \mathrm{ppm}$ in respect to the residue signals of solvents and recalculated to internal standard (TMS). The coupling constants were measured with a precision of $0.1 \mathrm{~Hz}$. Numeration of carbon atoms in naphthalimide nucleus, styryl fragment, and butyl group, used for the description of ${ }^{1} \mathrm{H}$ and ${ }^{13} \mathrm{C}$ NMR spectra of compounds $\mathbf{1}-\mathbf{5}$ are represented in Scheme 1. The assignment of signals was carried out using two-dimensional methods HSQC, HMBC, and ${ }^{1} \mathrm{H}$ COSY with pulse field gradients.

Mass spectra with electrospray ionization at the atmosphere pressure (electrospray ionization method, ESI) were registered in the mode of total scanning of positive ions masses with tandem dynamic mass spectrometer Finnigan LCQ Advantage. Melting point were determined in glass capillary using Mel-Temp device 
and were not corrected. Elemental analysis was carried out in the laboratory of microanalysis of the Institute of Organoelement Compounds of Russian Academy of Sciences. The control of the reaction and of purity of obtained compounds was performed using TLC with Sorbfil UV-254 (silica gel STX-1VE) and DC-Alufolien Kieselgel $60 \mathrm{~F}_{254}$ (Merck) plates. The column chromatography was carried out using silica gel Kieselgel 60, particle size was $0.063-$ $0.200 \mathrm{~mm}$ (Merck).

The absorption spectra were measured using two channel spectrometer Varian-Cary 5G. The fluorescence spectra were measured using spectrofluorimeter FluoroMax-3 at temperature $20 \pm 1{ }^{\circ} \mathrm{C}$. Observed fluorescence was registered perpendicular to exciting beam. The fluorescence spectra were corrected in respect to sensitivity of the photomultiplier. The solvents of spectroscopic grade (Sigma Aldrich, purity not less than 99.5\%) were used for the absorption and fluorescence spectra. The spectra were registered in solvents with a concentration of $\sim 10^{-6} \mathrm{~mol} \mathrm{~L}^{-1}$.

The fluorescence quantum yields were determined in air saturated solutions at temperature $20 \pm 1{ }^{\circ} \mathrm{C}$ in respect to coumarin 481 standard in acetonitrile $\left(\varphi^{\mathrm{fl}}=0.08\right) .{ }^{35}$ To calculate quantum yield following equation was used ${ }^{36}$

$$
\varphi_{i}^{\mathrm{fl}}=\varphi_{0} \frac{\left(1-10^{-D_{0}}\right) S_{i} n_{0}^{2}}{\left(1-10^{-D_{i}}\right) S_{0} n_{i}^{2}},
$$

where $\varphi^{\mathrm{fl}}{ }_{i}$ and $\varphi^{\mathrm{fl}}$ are the quantum yields, $D_{i}$ and $D_{0}$ are the absorptions, $S_{i}$ and $S_{0}$ are the integrals of fluorescence spectra of analyzed compound and standard, respectively; $n_{i}$ and $n_{0}$ are the refractive indices of solvents for studied compound and standard, respectively.

Time dependent fluorescence spectra were registered using a system consisting of spectrograph Chromex 250, connected to Hamamatsu 5680 streak camera with the module of fast scanning M5676 with a time resolution of 2 ps. Excitation pulses were generated using light optical parametric oscillator pumped by the fundamental emission of femtosecond laser system $\mathrm{Ti}-$ sapphire Femtopower Compact Pro. All values of lifetime of excited states were obtained using depolarized excitation light. Maximum pulse energy of the fluorescence excitation was not higher than $100 \mathrm{~nJ}$, average power was $0.1 \mathrm{~mW}$, pulse repetition rate was $1 \mathrm{kHz}$. The excitation beam of $0.1 \mathrm{~mm}$ diameter was focused onto quartz cuvette $(l=10 \mathrm{~mm})$. The analysis of florescence kinetics was carried out by curve fitting using method of Levenberg-Marquardt least squares applying the solutions of differential equations describing the behavior of one of the excited state in time without taking into account changes in the population of the ground state according to the equation

$$
\frac{d I}{d t}=\operatorname{Gauss}\left(t_{0}, \Delta t, A\right)-\frac{I(t)}{\tau}
$$

where $I(t)$ is the intensity of fluorescence, $\tau$ is the lifetime of the excited state, Gauss is the Gauss profile of exciting pulse, $t_{0}$ is the time position of maximum, $\Delta t$ is the pulse width, $A$ is the pulse amplitude. Initial conditions were $I(-\infty)=0$. By selecting the solution the values of $\chi^{2}$ (Pearson criterion) was always smaller than $1 \cdot 10^{-4}$, and correlation coefficient $R>0.999$. Error of calculation of the lifetime did not exceed $1 \%$. Fluorescence accumulation time in the experiments did not exceed $90 \mathrm{~s}$. The registration of the fluorescence spectra with time resolution has been made on the equipment of the Aquitaine Waves and Matter Laboratory, University of Bordeaux/CNRS (France).

Quantum chemical calculations were carried out with half empirical method PM6 $6^{37}$ using the software package MOPAC2012. Iterative procedure was continued as long as the molecular energy difference of two successive iterations did not exceed $0.01 \mathrm{kcal} \mathrm{mol}^{-1}$. Influence of solvent nature was taken into account in accordance with the model COSMO (Conductor like Screening Model), included in MOPAC-2012. It was assumed in the calculations that the solvent has a dielectric constant $\varepsilon=20$ and refractive index $n$ such that $n^{2}=2$.

5-Bromo-1,2-dihydroacenaphthylene (5). To the suspension of $10.0 \mathrm{~g}(0.065 \mathrm{~mol})$ 1,2-dihydroacenaphthylene (4) in $35 \mathrm{~mL}$ of DMF under continuous stirring the solution of $11.3 \mathrm{~g}(0.064 \mathrm{~mol})$ $\mathrm{N}$-bromosuccinimide in $35 \mathrm{~mL}$ of DMF was added drop by drop during $30 \mathrm{~min}$. After the addition of the solution was complete the reaction mixture was stirred for another $2 \mathrm{~h}$ at room temperature and then was poured into $1 \mathrm{~L}$ of water. Formed precipitate was separated by filtration and washed in the filter with ethanol. The product was purified by crystallization from methanol. The yield was $12.5 \mathrm{~g}(82 \%)$, m.p. $50-52{ }^{\circ} \mathrm{C}$ (see Ref. 38 : m.p. $51-52^{\circ} \mathrm{C}$ ). ${ }^{1} \mathrm{H}$ NMR spectrum $\left(400.13 \mathrm{MHz}, \mathrm{C}_{6} \mathrm{D}_{6}, 27^{\circ} \mathrm{C}\right), \delta: 3.21-3.36$ $\left(\mathrm{m}, 4 \mathrm{H}, 2 \mathrm{CH}_{2}\right) ; 7.04(\mathrm{~d}, 1 \mathrm{H}, \mathrm{H}(3), J=7.3 \mathrm{~Hz}) ; 7.23$ $(\mathrm{d}, 1 \mathrm{H}, \mathrm{H}(6), J=7.0 \mathrm{~Hz}) ; 7.45(\mathrm{dd}, 1 \mathrm{H}, \mathrm{H}(7), J=8.3 \mathrm{~Hz}, J=$ $=7.0 \mathrm{~Hz}) ; 7.56(\mathrm{~d}, 1 \mathrm{H}, \mathrm{H}(4), J=7.3 \mathrm{~Hz}) ; 7.67(\mathrm{~d}, 1 \mathrm{H}, \mathrm{H}(8), J=8.3 \mathrm{~Hz})$.

6-Bromobenzo[d,e]isochromene-1,3-dione (6). The mixture of $12.5 \mathrm{~g}(0.053 \mathrm{~mol}) 5$-brormoacenaphtene $(\mathbf{5})$ and $125 \mathrm{~mL}$ of acetic acid was heated to $90^{\circ} \mathrm{C}$. To this stirred solution $78.0 \mathrm{~g}(0.262 \mathrm{~mol})$ $\mathrm{Na}_{2} \mathrm{Cr}_{2} \mathrm{O}_{7} \cdot 2 \mathrm{H}_{2} \mathrm{O}$ was added by small portions in order to maintain temperature not higher than $90^{\circ} \mathrm{C}$. Then reaction mass was heated to reflux and was kept at reflux with condenser for $5.5 \mathrm{~h}$. Afterwards, the reaction mass was cooled to room temperature and poured into $750 \mathrm{~mL}$ of water. Formed precipitate was separated by the filtration and washed on the filter by diluted hydrochloric acid and then by water. This precipitate was suspended in $500 \mathrm{~mL}$ of $10 \%$ aqueous solution of $\mathrm{Na}_{2} \mathrm{CO}_{3}$ and boiled for $1 \mathrm{~h}$. Obtained solution was cooled down to room temperature and insoluble precipitate was separated by filtration. The filtrate was acidified by concentrated hydrochloric acid, formed precipitate of 4-bromonaphtalic acid was separated by filtration, washed with water and dried. In order to obtain anhydride the product was recrystallized from acetic acid. The yield was $6.6 \mathrm{~g}$ (44\%), m.p. $218-220{ }^{\circ} \mathrm{C}$ (see Ref. 39: m.p. $\left.219-220^{\circ} \mathrm{C}\right) .{ }^{1} \mathrm{H}$ NMR $\left(400.13 \mathrm{MHz}\right.$, DMSO-d 6 , $\left.27^{\circ} \mathrm{C}, \delta\right)$ : $8.05(\mathrm{dd}, 1 \mathrm{H}, \mathrm{H}(6), J=7.5 \mathrm{~Hz}, J=7.9 \mathrm{~Hz}) ; 8.27$ (d, $1 \mathrm{H}, \mathrm{H}(3)$, $J=7.5 \mathrm{~Hz}) ; 8.37$ (d, $1 \mathrm{H}, \mathrm{H}(2), J=7.5 \mathrm{~Hz}) ; 8.61-8.65(\mathrm{~m}, 2 \mathrm{H}$, $\mathrm{H}(5), \mathrm{H}(7))$.

6-Bromo-2-butyl-1 $H$-benzo $[d, e]$ isoquinoline-1,3(2H)-dione (7). To suspension of $500 \mathrm{mg}(1.8 \mathrm{mmol})$ of 4-bromonaphtalic anhydride 6 in $35 \mathrm{~mL}$ of ethanol $228 \mu \mathrm{L}$ ( $2.3 \mathrm{mmol})$ of butylamine was added. The reaction mass was heated to reflux, kept at reflux for $6 \mathrm{~h}$, and cooled down to room temperature. Precipitate of $N$-substituted naphthalimide was separated by filtration, washed on filter with $5 \%$ hydrochloric acid, $10 \%$ solution of $\mathrm{Na}_{2} \mathrm{CO}_{3}$, water, and ethanol. The product was dried at $80^{\circ} \mathrm{C}$. The yield was $534 \mathrm{mg}$ (89\%), m.p. $100-102{ }^{\circ} \mathrm{C}$ (see Ref. 40: m.p. $101-102{ }^{\circ} \mathrm{C}$ ). ${ }^{1} \mathrm{H}$ NMR (400.13 MHz, DMSO-d $\left.6,21^{\circ} \mathrm{C}, \delta\right): 0.94$ (t, $3 \mathrm{H}, \mathrm{H}(12)$, $J=8.4 \mathrm{~Hz}) ; 1.29-1.40(\mathrm{~m}, 2 \mathrm{H}, \mathrm{H}(11)) ; 1.56-1.65$ (m, $2 \mathrm{H}$, 
$\mathrm{H}(10)) ; 4.03$ (т, $2 \mathrm{H}, \mathrm{H}(9), J=8.4 \mathrm{~Hz}) ; 8.00$ (dd, $1 \mathrm{H}, \mathrm{H}(6), J=$ $=7.3, J=8.5 \mathrm{~Hz}) ; 8.21(\mathrm{~d}, 1 \mathrm{H}, \mathrm{H}(3), J=8.1 \mathrm{~Hz}) ; 8.32(\mathrm{~d}, 1 \mathrm{H}$, $\mathrm{H}(2), J=8.1 \mathrm{~Hz}) ; 8.52-8.59$ (м, $2 \mathrm{H}, \mathrm{H}(7), \mathrm{H}(5))$. MS (ESI), found: $m / z 331.07[\mathrm{M}]^{+}$, calculated: 331.02 .

Synthesis of compounds 1-3 (general procedure). $1 \mathrm{mmol}$ of 4-bromo- $N$-butylnaphthalimide 7, $0.01 \mathrm{mmol}$ of palladium acetate, $0.06 \mathrm{mmol}$ of tris-(orto-tolyl)phosphine, $1 \mathrm{~mL}$ of triethylamine, and $1.2 \mathrm{mmol}$ of corresponding styrene were dissolved in $10 \mathrm{~mL}$ of DMF in argon atmosphere. The reaction mass was kept at $105^{\circ} \mathrm{C}$ for $15-24 \mathrm{~h}$, then cooled down to room temperature, diluted with water, and extracted with dichloromethane. The extract was dried over anhydrous $\mathrm{MgSO}_{4}$, evaporated, and the residue was separated using silica gel with hexane-ethyl acetate as eluent with increasing gradient of eluent polarity. Obtained product was recrystallized from ethanol.

2-Butyl-6-(4-methoxystyryl)- $1 H$-benzo $[d, e]$ isoquinoline1,3(2H)-dione (1). The yield was $38 \%$, m.p. $140-143{ }^{\circ} \mathrm{C}$. ${ }^{1} \mathrm{H}$ NMR (400.13 MHz, $\left.\mathrm{CDCl}_{3}, 22{ }^{\circ} \mathrm{C}, \delta\right): 0.99$ (t, $3 \mathrm{H}, \mathrm{H}(12)$, $J=8.4 \mathrm{~Hz}) ; 1.43-1.50(\mathrm{~m}, 2 \mathrm{H}, \mathrm{H}(11)) ; 1.69-1.77$ (m, $2 \mathrm{H}, \mathrm{H}(10))$; $3.88\left(\mathrm{~s}, 3 \mathrm{H}, \mathrm{OCH}_{3}\right) ; 4.20$ (t, $\left.2 \mathrm{H}, \mathrm{H}(9), J=8.4 \mathrm{~Hz}\right) ; 6.98(\mathrm{~d}, 2 \mathrm{H}$, $\mathrm{H}(16), \mathrm{H}(18), J=8.6 \mathrm{~Hz}) ; 7.31$ (d, $1 \mathrm{H}, \mathrm{H}(13 \mathrm{~b}), J=16.0 \mathrm{~Hz}) ; 7.59$ (d, $2 \mathrm{H}, \mathrm{H}(15), \mathrm{H}(19), J=8.6 \mathrm{~Hz}) ; 7.72-7.81$ (m, $2 \mathrm{H}, \mathrm{H}(13 \mathrm{a})$, $\mathrm{H}(6)) ; 7.98(\mathrm{~d}, 1 \mathrm{H}, \mathrm{H}(3), J=7.7 \mathrm{~Hz}) ; 8.56-8.61(\mathrm{~m}, 2 \mathrm{H}, \mathrm{H}(2)$, $\mathrm{H}(5)) ; 8.63(\mathrm{~d}, 1 \mathrm{H}, \mathrm{H}(7), J=8.3 \mathrm{~Hz}) .{ }^{13} \mathrm{C} \mathrm{NMR}(150.93 \mathrm{MHz}$, $\left.\mathrm{CDCl}_{3}, 22{ }^{\circ} \mathrm{C}, \delta\right): 13.98(\mathrm{C}(12)), 20.89$ (C(11)), 30.56 (C(10)), $40.45(\mathrm{C}(9)), 55.16\left(\mathrm{OCH}_{3}\right), 114.56(\mathrm{C}(16), \mathrm{C}(18)), 121.56(\mathrm{C}(1))$, 121.76 (C(13a)), 123.68 (C(8)), 123.97 (C(3)), 126.84 (C(8a)), 127.23 (C(6)), 129.63 (C(15), C(19)), 129.79 (C(14)), 130.06 (C(4a)), $130.11(\mathrm{C}(5)), 130.23(\mathrm{C}(7)), 131.81(\mathrm{C}(2)), 135.67$ (C(13b)), 142.16 (C(4)), 161.07 (C(17)), 163.97 (C(8b)), 164.08 (C(8c)). MS (ESI), found: $m / z 385.21[\mathrm{M}]^{+}$, calculated: 385.17 . Found (\%): C, 77.94; H, 6.11; N, 3.70. $\mathrm{C}_{25} \mathrm{H}_{23} \mathrm{NO}_{3}$. Calculated (\%): C, 77.89; H, 6.02; N, 3.64 .

2-Butyl-6-(3,4-dimethoxystyryl)-1 $H$-benzo[ $[d, e]$ isoquonoline1,3(2H)-dione (2). The yield was $18 \%$, m.p. $155-157{ }^{\circ} \mathrm{C}$. ${ }^{1} \mathrm{H}$ NMR (400.13 MHz, $\left.\mathrm{CDCl}_{3}, 21{ }^{\circ} \mathrm{C}, \delta\right): 0.99$ (t, $3 \mathrm{H}, \mathrm{H}(12)$, $J=8.4 \mathrm{~Hz}) ; 1.43-1.52(\mathrm{~m}, 2 \mathrm{H}, \mathrm{H}(11)) ; 1.70-1.78(\mathrm{~m}, 2 \mathrm{H}, \mathrm{H}(10))$; $3.96\left(\mathrm{~s}, 3 \mathrm{H}, \mathrm{OCH}_{3}\right) ; 4.02\left(\mathrm{~s}, 3 \mathrm{H}, \mathrm{OCH}_{3}\right) ; 4.20(\mathrm{t}, 2 \mathrm{H}, \mathrm{H}(9), J=$ $=8.4 \mathrm{~Hz}) ; 6.94(\mathrm{~d}, 1 \mathrm{H}, \mathrm{H}(18), J=8.2 \mathrm{~Hz}) ; 7.18-7.24(\mathrm{~m}, 2 \mathrm{H}$, $\mathrm{H}(15), \mathrm{H}(19)) ; 7.30$ (d, $1 \mathrm{H}, \mathrm{H}(13 \mathrm{~b}), J=16.0) ; 7.72-7.82(\mathrm{~m}, 2 \mathrm{H}$, $\mathrm{H}(13 \mathrm{a}), \mathrm{H}(6)) ; 7.98$ (d, $1 \mathrm{H}, \mathrm{H}(3), J=7.7 \mathrm{~Hz}) ; 8.56-8.62(\mathrm{~m}, 2 \mathrm{H}$, $\mathrm{H}(2), \mathrm{H}(5)) ; 8.65$ (d, $1 \mathrm{H}, \mathrm{H}(7), J=8.3 \mathrm{~Hz}) .{ }^{13} \mathrm{CNMR}(150.93 \mathrm{MHz}$, $\left.\mathrm{CDCl}_{3}, 21^{\circ} \mathrm{C}, \delta\right): 13.98(\mathrm{C}(12)), 20.89$ (C(11)), 30.56 (C(10)), 40.45 (C(9)), $55.26\left(2 \mathrm{OCH}_{3}\right), 109.78$ (C(19)), 112.01 (C(18)), 121.63 (C(15)), 121.86 (C(1)), 122.06 (C(13a)), 123.88 (C(8)), $123.97(\mathrm{C}(3)), 127.44(\mathrm{C}(6)), 129.83(\mathrm{C}(8 \mathrm{a})), 130.69(\mathrm{C}(14))$, $130.86(\mathrm{C}(4 \mathrm{a})), 131.11(\mathrm{C}(5)), 131.89(\mathrm{C}(7)), 131.91(\mathrm{C}(2)), 136.07$ (C(13b)), $142.16(\mathrm{C}(4)), 149.75(\mathrm{C}(16)), 150.07$ (C(17)), 164.37 (C(8b)), $164.48(\mathrm{C}(8 \mathrm{c}))$. MS (ESI), found: $m / z 415.22[\mathrm{M}]^{+}$, calculated: 415.18. Found (\%): C, 75.21; H, 6.13; N, 3.43. $\mathrm{C}_{26} \mathrm{H}_{25} \mathrm{NO}_{4}$. Calculated (\%): C, 75.15; H, 6.07; N, 3.37.

2-Butyl-6-(4-(dimethylamino)styryl)- $1 \mathrm{H}$-benzo [d,e]isoquionoline-1,3(2H)-dione (3). The yield was $28 \%$, m.p. $181-184^{\circ} \mathrm{C}$. ${ }^{1} \mathrm{H}$ NMR (400.13 MHz, $\mathrm{CD}_{3} \mathrm{Cl}, 23{ }^{\circ} \mathrm{C}, \delta$ ): 0.98 (t, $3 \mathrm{H}, \mathrm{H}(12)$, $J=8.4) ; 1.42-1.51$ (m, $2 \mathrm{H}, \mathrm{H}(11)) ; 1.69-1.78$ (m, $2 \mathrm{H}, \mathrm{H}(10)$ ); $3.07\left(\mathrm{~s}, 6 \mathrm{H}, \mathrm{N}\left(\mathrm{CH}_{3}\right)_{2}\right) ; 4.19(\mathrm{t}, 2 \mathrm{H}, \mathrm{H}(9), J=8.4 \mathrm{~Hz}) ; 6.73-7.00$ (m, $2 \mathrm{H}, \mathrm{H}(16), \mathrm{H}(18)) ; 7.33$ (d, $1 \mathrm{H}, \mathrm{H}(13 \mathrm{~b}), J=16.0 \mathrm{~Hz})$; 7.58 (d, $2 \mathrm{H}, \mathrm{H}(15), \mathrm{H}(19), J=8.6 \mathrm{~Hz}) ; 7.69-7.80$ (d, $2 \mathrm{H}, \mathrm{H}(6)$, $\mathrm{H}(13 \mathrm{a})) ; 7.99(\mathrm{~d}, 1 \mathrm{H}, \mathrm{H}(3), J=7.7 \mathrm{~Hz}) ; 8.55-8.65(\mathrm{~m}, 3 \mathrm{H}$, $\mathrm{H}(2), \mathrm{H}(5), \mathrm{H}(7)) .{ }^{13} \mathrm{C}$ NMR $\left(150.93 \mathrm{MHz}, \mathrm{CDCl}_{3}, 22^{\circ} \mathrm{C}, \delta\right)$ : 13.02 (C(12)), 20.03 (C(11)), 29.16 (C(10)), 38.76 (C(9)), 38.94 $\left(2 \mathrm{~N}\left(\mathrm{CH}_{3}\right)_{2}\right), 112.06(\mathrm{C}(16), \mathrm{C}(18)), 117.96(\mathrm{C}(13 \mathrm{a})), 119.87$ (C(1)), 122.12 (C(3)), 122.97 (C(8)), 124.84 (C(8a)), 126.23 (C(6)), 129.07 (C(15)), C(19)), 129.79 (C(14)), 130.39 (C(4a)), $130.56(\mathrm{C}(5)), 130.81(\mathrm{C}(7)), 130.89(\mathrm{C}(2)), 136.07$ (C(13b)), 142.01 (C(4)), 144.07 (C(17)), 161.97 (C(8b)), 162.08 (C(8c)). MS (ESI), found: $m / z 398.27[\mathrm{M}]^{+}$, calculated: 398.20 . Found (\%): C, 78.43; H, 6.56; N, 7.08. $\mathrm{C}_{26} \mathrm{H}_{26} \mathrm{~N}_{2} \mathrm{O}_{2}$. Calculated (\%): C, 78.35; H, 6.58; N, 7.03.

The work was performed with financial support of ERA.NET RUS Plus 311-DONOS Project and Ministry of Education and Science of the Russian Federation (Agreement No. 14.616.21.0037(RFMEFI61615X0037)).

\section{References}

1. J. R. Lakowicz, Principles of Fluorescent Spectroscopy, Springer science + Business Media, New York, 2006, p. 960.

2. A. V. Feofanov, Usp. Biolog. Khim. [Biolog. Chem. Rev.], 2007, 47, 371 (in Russian)

3. D. P. Millar, Curr. Opin. Struct. Biol., 1996, 6, 322.

4. C. A. Royer, Chem. Rev., 2006, 106, 1769.

5. A. Schepartz, R. L. Gonzalez, Curr. Opin. Chem. Biol., 2011, 15, 749 .

6. G. P. C. Drummen, Molecules, 2012, 17, 14067.

7. A. V. Kulinich, A. A. Ishchenko, Russ. Chem. Rev. (Engl. Transl.), 2009, 78, 141.

8. N. S. James, Y. Chen, P. Joshi, T. Y. Ohulchanskyy, M. Ethirajan, M. Henary, L. Strekowsk, R. K. Pandey, Theranostics, 2013, 3, 692.

9. N. S. James, T. Y. Ohulchanskyy, Y. Chen, P. Joshi, X. Zheng, L. N. Goswami, R. K. Pandey, Theranostics, 2013, 3, 703.

10. I. Grabchev, T. Konstantinova, Dyes Pigm., 1997, 33, 197.

11. B. May, X. Poteau, D. Yuan, R. G. Brown, Dyes Pigm., 1999, 42, 79 .

12. C. Siegers, B. Olàh, U. Würfel, J. Hohlebinger, A. Hinsch, R. Haag, Solar Energ. Mater. Solar Cells, 2009, 93, 552.

13. G. Jiang, S. Wang, W. Yuan, L. Jiang, Y. Song, H. Tian, D. Zhu, Chem. Mater., 2006, 18, 235.

14. G. Tu, Q. Zhou, Y. Cheng, Y. Geng, L. Wang, D. Ma, X. Jing, F. Wang, Synth. Met., 2005, 152, 233.

15. Z. Zhou, M. Yu, H. Yang, K. Huang, F. Li, T. Yi, C. Huang, Chem. Commun., 2008, 3387.

16. P. A. Panchenko, Yu. V. Fedorov, O. A. Fedorova, G. Jonusauskas, Phys. Chem. Chem. Phys., 2015, 17, 22749.

17. M. Sawa, T.-L. Hsu, T. Itoh, M. Sugiyama, S. R. Hanson, P. K. Vogt, Ch.-H. Wong, Proc. Nat. Acad. Sci. USA, 2006, 103, 12371.

18. W. W. Stewart, J. Am. Chem. Soc., 1981, 103, 7615.

19. M. S. Alexiou, V. Tychopoulos, S. Ghorbanian, J. H. P. Tyman, R. G. Brown, P. I. Brittain, J. Chem. Soc., Perkin Trans. 2, 1990, 837.

20. J. L. Magalhães, R. V. Pereira, E. R. Triboni, P. Berci Filho, M. H. Gehlen, F. C. Nart, Photochem. Photobiol. A: Chemistry, 2006, 183, 165.

21. K. Rurack, U. Resch-Genger, J. L. Bricks, M. Spielesa, Chem. Commun., 2000, 2103.

22. L. Duan, Y. Xu, X. Qian, Y. Zhang, Y. Liu, Tetrahedron Lett., 2009, 50, 22.

23. H.-H. Lin, Y.-Ch. Chan, J.-W. Chen, Ch.-Ch. Chang, J. Mater. Chem., 2011, 21, 3170. 
24. S. Paramonov, S. Delbaere, O. Fedorova, Yu. Fedorov, V. Lokshin, A. Samat, G. Vermeersch, J. Photochem. Photobiol. A, 2010, 209, 111.

25. E. Von Lippert, Z. Electrochem., 1957, 61, 962.

26. N. Mataga, Y. Kaifu, M. Koizumi, Bull. Chem. Soc. Jpn., 1956, 29, 465.

27. G. J.-F. Demets, E. R. Triboni, E. B. Alvarez, G. M. Arantes, P. B. Filho, M. J. Politi, Spectrochim. Acta, Part A, 2006, 63, 220.

28. S. Saha, A. Samanta, J. Phys. Chem. A, 2002, 106, 4763.

29. E. N. Viktorova, D. G. Pereyaslova, E. G. Yushko, Zh. Fiz. Khimii [Russ. J. Phys Chem.] 1966, 40, 1783 (in Russian).

30. S. L. Dmitruk, S. I. Druzhinin, R. A. Minakova, A. I. Bedrik, B. M. Uzhinov, Russ. Chem. Bull. (Engl. Transl.), 1997, 46, 2027 [Izv. Akad. Nauk, Ser. Khim., 1997, 2140].

31. Y. A. Mednykh, Y. A. Manaev, V. V. Volchkov, B. M. Uzhinov, Russ. J. Gen. Chem. (Engl. Transl.), 2004, 74, 1728 [Zh. Obsch. Khimii, 2004, 74, 1858].
32. W. Rettig, Top. Curr. Chem., 1994, 169, 253.

33. W. Rettig, E. Lippert, J. Mol. Struct., 1980, 61, 17.

34. A. B. J. Parusel, Chem. Phys. Lett., 2001, 340, 531.

35. S. Nad, M. Kumbhakar, H. Pal, J. Phys. Chem. A, 2003, 107, 4808.

36. C. L. Renschler, L. A. Harrah, Anal. Chem., 1983, 55, 798.

37. J. J. P. Stewart, J. Mol. Model., 2007, 13, 1173.

38. S. D. Ross, M. Finkelstein, R. C. Petersen, J. Am. Chem. Soc., $1958,80,4327$.

39. M. Shahid, P. Srivastava, A. Misra, New J. Chem., 2011, 35, 1690.

40. P. Stange, K. Fumino, R. Ludwig, Chem. Eur. J., 2013, 19, 2990. 